\title{
The Effect of Teaching Cohesive Devices on IELTS Writing Task 2 of Iranian Foreign Language Learners
}

\author{
Leila Kamelifar \\ Refah Humanitarian Science Faculty \\ Mardom St., Baharestan Sq., Tehran, Iran
}

Tel: 912-514-4930Ｅ-mail: leilakamelifar@yahoo.com

Received: August 5, 2017 Accepted: August 24, 2017 Published: August 25, 2017

doi:10.5296/jsel.v5i1.11749 URL: https://doi.org/10.5296/jsel.v5i1.11749

\begin{abstract}
Obtaining good scores in IELTS has become a concern for many foreign language learners throughout the world. Therefore, any relevant research to pave the way of applicants' achievement may be considered significant. This study deals with an indispensable element of IELTS writing tasks as teaching cohesive devices and it verifies the effect on writing performance of IELTS task 2. To this end, 30 participants at intermediate level took an IELTS test writing task 2 as the pretest. Then, they went under a 10 session treatment program to learn cohesive devices. At the end, they took a parallel form of IELTS task 2. The scores were obtained. The inter-rater reliability was met. The results of the paired Samples $T$-test showed that there was a significant difference between the mean scores of pre and post- tests of the participants after being exposed to cohesive devices treatment.
\end{abstract}

Keywords: IELTS writing task 2, cohesive devices 


\section{Introduction}

One of the most prevalent problems of IELTS candidates about which they complain and lose scores, is the way cohesive devices or linkers are used. In the marking criteria for task 2 essays and writing task 1 reports, coherence and cohesion accounts for $25 \%$ of the candidates' scores (ieltsfocus.com, 2017). As a result, it is significant to note this problem. It means that the candidates should be explicitly informed about what cohesive devices are and how they are scored. According to the international scoring system of IELTS, the role of cohesive devices in IELTS writing achievement becomes more considerable.

- Band 5 : "makes inadequate, inaccurate or over use of cohesive devices"

- Band 7 : "uses a range of cohesive devices appropriately although there may be some under/over-use

- Band 8: "manages all aspects of cohesion well"( ieltsfocus.com, 2017).

\section{Review of the Related Literature}

Saadat and Fayaz Dastgerdi (2014) argue that the ability to write in English is considered to be a valuable skill to the learners majoring in English as a second/foreign language. However, not all the learners possess the same level of L2 writing ability in spite of the courses they take at the university. Previous researches has yielded many results about factors that may contribute to L2 writing performance.

Saadat and Fayaz Dastgerdi (2014) also carried out a research to explore the correlations of L2 writing ability of Iranian learners and the way their writing scores are influenced by their L2 writing strategy use. They accordingly concluded that instructors of L2 writing courses are advised to help learners in improving their language proficiency first and also to become more cautious when responding to learner writers' attempts at developing their writing ability.

In the same line, Saricaoglu and Arican (2009) argue that there is a correlation between fluid reasoning ability (i.e., application of cohesive devices, Marandi, 2002) and the learners' success in L2 writing and grammar. Moreover, Mahdavi's study (2008) indicates a correlation between general intelligence and both TOEFL and IELTS listening comprehension performance. Although, there has been a bunch of exam question types of IELTS writing tasks in Iran, the experimental research falls rather short in the strengthening processes of developing IELTS writing tasks. Kamelifar and Salimi (2016) made an extensive research on the contributing elements to appropriate application of conjunctions in general and partially on IELTS writing task 2. This study was an attempt to find the answer to this research question.

Q: Does teaching cohesive devices have any effect on IELTS writing task 2 of Iranian foreign language learners?

To scrutinize the above-mentioned research questions empirically, the following hypothesis was stated. 
HO: Teaching cohesive devices does not have any effect on IELTS writing task 2 of Iranian foreign language learners.

\subsection{Cohesive Devices and their Functions}

According to Eggins (1994), cohesive writing is a kind of writing in which sentences are well held together. Cohesive writing is easy to follow because it uses language effectively to guide the reader. It refers to how a writer creates and expresses the logical relationships between the parts of a text and how she conveys an intended meaning.

In English, cohesion is achieved through making the logical relationships between ideas, so that the reader can easily understand the relationship between the parts of a text. The logical relationship between clauses, sentences, and paragraphs can be expressed by conjunctions (and, or, because, so) or they can be expressed by prepositional phrases (after that, in contrast) or adverbs (thus, alternatively) (Aronson, 2006).

Here are some of the most common conjunctive adverbs:

- Also, besides, furthermore, additionally, so (additional or consequential)

- Therefore, thus, consequently, so (consequential)

- Alternatively, similarly (comparative)

- However,nevertheless, otherwise(contrastive)

In addition to conjunctions that join clauses together, there are words that create cohesion between sentences, and also between two or several paragraphs. Using conjunctions, writers can restore different concepts to their writings, such as logic and reason, addition, contrast, conclusion, concession, and etc. These words can be: prepositional phrases (on the contrary, in spite of); a preposition introducing a noun phrase (besides the suitable conditions); a preposition introducing an 'ing' verb (besides finding suitable conditions); and adverbs (alternatively) (Oshima \& Hogue, 1991).

\section{Method}

\subsection{Participants}

The researcher selected 63 Psychology students studying English as a foreign language. They all took PET (Preliminary English Test) to be checked regarding their level of proficiency. The extreme scores and outliers were excluded and the remaining participants were 30 with the intermediate general proficiency level and the mean age of 23 .

\section{Procedure}

The first part of the procedure was teaching participants how to develop task 2 . They were also 
taught an argumentative article with four different parts, which were introduction, argument, counter argument and conclusion. Then, they all took an IELTS writing task 2 as a pre-test. The topic was "Jobs that governments offer to the people should be first compatible with the people interest rather than their university majors. To what extent do you agree or disagree?"

Subsequently, all the participants went through the process of cohesive devices treatment for 10 sessions, each one lasted for 45 minutes. The approach to teach grammar was inductive way of grammar teaching. The researcher provided the participants with some examples of each targeted cohesive device within full sentences using vocabularies that participants already knew. The reason behind this was that to make the linkers meaningful, the context had to be to the participants' comprehension. Also, participants needed to figure out how discourse markers bind the ideas to each other logically. The researcher wrote each sentence consisting of one conjunctive adverb on the board, read the sentences one by one and made sure of participants' comprehension. It is noteworthy that in order to assure about the comprehensibility of the presented examples, the researcher used participants' mother tongue (i.e., Persian) off and on. Then, she referred the learners to the contextualized form of those linkers found in text-book. The examples were mostly from "Select for Reading" (Intermediate) by Lee and Gunderson (2002). The book was selected due to the appropriate examples in context congruent with the participants' level of proficiency. Also, the abundantly authentic texts which were cohesive and coherent, could ease and smooth teaching conjunctions. Participants read the texts and underlined the cohesive devices after researcher's explanations. When the treatment was over, an immediate post-test in IELTS writing task 2 was conducted. It was a parallel form of pre-test. The given topic was "People in industrialized countries work too much and usually ignore their family ties for money making." To what extend do you agree?

\section{Results}

To answer the research question "Does teaching cohesive devices have any effect on IELTS writing task 2 of Iranian foreign language learners?", the researcher administered an IELTS writing task 2 for the participants when the treatment was over. To see if there was any statistically significant difference between the mean scores of participants in pre and post-test in IELTS task 2, the researcher administered a paired samples $t$-test.

Table 1. Participants' Descriptive Statistics for IELTS writing Task 2

\begin{tabular}{lllccl}
\hline \multicolumn{5}{c}{ Paired Samples Statistics } \\
\hline \multirow{4}{*}{ Pair 1 } & Mean & $\mathrm{N}$ & Std. Deviation & Std. Error Mean \\
& & & & & \\
& Pre & 3.00 & 30 & 1.00 & .00 \\
& Post & 4.00 & 30 & 1.00 & .00 \\
\hline
\end{tabular}


Table 2. The Results of Exposure to cohesive devices

\begin{tabular}{lccllcccc}
\hline \multicolumn{10}{c}{ Paired Differences } \\
\hline & Mean & Std. & Std. Error & Lower & Upper & t & df & Sig \\
pre-post &.$/ 00$ &.$/ 00$ &.$/ 00$ & -1.00 &.$/ 00$ & -5.00 & 29 & .00 \\
\hline
\end{tabular}

A paired samples $t$-test was administered to evaluate the effect of exposure to cohesive devices on improving the scores of IELTS writing task 2 . There was a statistically significant difference between the pre-test $(\mathrm{M}=3, \mathrm{SD}=1)$ and post-test $(\mathrm{M}=4, \mathrm{SD}=1), t(29)=5.00, p$ $<.001$. Therefore, the null hypothesis HO (1) stating that exposure to cohesive devices does not have any statistically significant effect on IELTS writing task 2 of Iranian intermediate learners, is rejected. To obtain an inter-rater reliability, the papers were corrected by another researcher. Like most correlation statistics, the kappa can range from -1 to +1 . Kappa Coefficient was obtained as $K=0.62$.

Table 3. The Results of Kappa Coefficient for Inter-rater Reliability in IELTS Writing Skill

\begin{tabular}{llllll}
\hline \multicolumn{2}{l}{ Item-Total Statistics } & & & & \\
& $\begin{array}{l}\text { Scale Mean if } \\
\text { Item Deleted }\end{array}$ & $\begin{array}{l}\text { Scale Variance } \\
\text { if Item Deleted }\end{array}$ & $\begin{array}{l}\text { Kappa } \\
\text { Coefficient }\end{array}$ & $\begin{array}{l}\text { Squared } \\
\text { Multiple } \\
\text { Correlation }\end{array}$ & $\begin{array}{l}\text { Cronbach's } \\
\text { Alpha if Item } \\
\text { Deleted }\end{array}$ \\
\cline { 3 - 5 } Gex1 & 3.00 & 3.00 & 0.62 & 0.74 & 0.78 \\
Gex2 & 3.00 & 2.00 & 0.62 & 0.74 & 0.78 \\
\hline
\end{tabular}

\section{Discussion and Conclusion}

Furthermore, according to Chazan (2000), creating contexts for authentic reasoning and practical skills likely paved the way for learners to learn the material in a less virtual atmosphere and feel the reasons much closer to the real world. According to Zahner and Moschkovich (2010), group work gives chances to learners to be involved in classroom discourse, to develop a shared understanding of their ideas, and increase the accountability of their choices. Also, participants during group discussion applied shared prior life experiences so that to reflect on a solution to a problem. Zahner and Moschkovich (2010) assert that when he focus of the items regarding reasoning and sense making is in accordance with current policies and real life realizations, teaching and learning processes would be strengthened. Moreover, the administration of an IELTS writing task 2. Test time limitation and other test conditions were based on IELTS standards except the familiarity with the topic from the pre-test. Participants took the IELTS writing task 2 after being exposed to cohesive devices for 450 minutes. As the results of the post-test indicated, there was a statistically significant difference between the mean scores of pre and post-test. The basis of IELTS writing task 2, is 
the application of linkers that participants learnt how to use them in writing sessions treatment. What was novel based on the results of the present study was that EFL learners who are sometimes concerned about the results of their IELTS writing scores may have more promising future through thoughtfully planned linkers treatment.

\section{References}

Aronson, T. (2006). English grammar digest. New York: Prentice Hall.

Kamelifar, L., \& Salimi, E. A. (2016). The effect of exposure to fluid intelligence components on learning sentence connectors of foreign language learners. Journal of Written Language \& Literacy, 19(1), 114-130. https://doi.org/10.1075/wll.19.2

Lee, L., \& Gunderson, E. (2002). Select readings. Oxford: OUP.

Oshima, A., \& Hogue, A. (1991). Writing academic English. California: Addison and Wesley.

Saadat, M., \& Fayaz Dastgerdi, M. (2014). Correlates of L2 writing ability of Iranian learners majoring in English. Social \& Behavioral Sciences, 98, 1572-1579. https://doi.org/10.1016/j.sbspro.2014.03.580

Saricaoglu, A., \& Arican, A. (2009). A study of multiple intelligences, foreign Language success, and some selected variables. Journal of Theory \& Practice in Education, 5(2), 110-122.

Zahner, W., \& Moschkovich, J. (2010). Talking while computing in groups: The not so private functions of computational private speech in mathematical discussions. Mind, Culture, \& Activity, 17, 265-268. https://doi.org/10.1080/10749030903515213

\section{Copyright Disclaimer}

Copyright for this article is retained by the author(s), with first publication rights granted to the journal.

This is an open-access article distributed under the terms and conditions of the Creative Commons Attribution license (http://creativecommons.org/licenses/by/3.0/). 